\title{
Critical theory and technology
}

Feenberg's critical theory of technology is to a large extent constructed through a synthesis of concepts from several predecessor theories, each of them important to his work in different ways, and each a source of concepts that he modifies in order to incorporate them into his own syncretic framework. This chapter describes the overarching rationale of Feenberg's intellectual project, with reference to some of these sources. It suggests that the result is a new system in which concepts take on altered significance and are made to do quite different work than they did in the earlier theories. Exploring in detail the new philosophy that emerges is the principal task of this book.

Looking at the way he engages with the ideas of Marx, Weber and earlier critical theorists makes it possible to identify the problems Feenberg is trying to solve with reference to what he sees as the crucial lacunae, errors and unsolved problems in his predecessors' work. It also clarifies the meanings of key terms in Feenberg's own corpus, for example when Feenberg introduces the idea of 'democratic rationalisation', a phrase that might seem almost oxymoronic if its terms were not properly contextualised in the works of scholars who assigned them specific meanings. Moreover, to establish the key criteria against which Feenberg's work as a whole ought to be judged it is important to grasp his main theoretical and practical priorities, and these emerge most clearly when he engages with other work in the critical theory tradition. Even his choice of key sources is itself revealing of Feenberg's overall problematic and of the conceptual innovations he introduces.

Feenberg's project is deeply informed by Marx and Marxism, though his main questions, which concern the politics of technology design, were almost completely overlooked in Marx's own work. Of special importance is Marx's concept of human self-realisation, a theme that informs all of Marx's work from his earliest writings, through Capital 
to his final reflections on the historical process (Stedman-Jones 2016). Marx was concerned with the social and historical conditions in which every human individual might be enabled to flourish and fulfil their potential. He referred to this as the 'all round development of each individual' (Marx and Engels 1982: 117). He speculated (infrequently, it should be noted) that in a society with advanced technology and socialist economic relations people would be freed from drudgery and enforced labour so that everyone could cultivate all their talents, writing plays in the morning, hunting in the afternoon and doing a bit of literary criticism after dinner.

This vision, which is a normative shibboleth of socialist ideology, is essentially preserved in Feenberg's critical theory, where it is technology as much as capitalist economic and social forms of organisation that prevents it from being realised. The paradox that technology, which Marx believed made his vision feasible by greatly enhancing human productive power, should be one of the forces ranged against the self-realisation of the species is already there in Marx's writings. Feenberg's innovation is to tackle it head-on, and his whole theory can be read as an attempt to resolve this problem in Marx's work.

Marx's problematic was taken over in the twentieth century by the Frankfurt School of critical theory, and this movement is the second key source for Feenberg's theory. Famously, thinkers of the Frankfurt School combined Marx's insights on capitalism and the new forms of authority and social power associated with it, including the authority of machinery, with Max Weber's thesis that capitalist modernity is a social formation in the grip of 'rationalisation'. The increased emphasis on instrumental efficiency that runs through modern institutional forms combines with a capitalist economy to produce new intensities of domination and associated human anguish. This leads Adorno and Horkheimer to characterise modern capitalism as a 'total society which embraces all relations and emotions' and eliminates any vestige of individuality by imposing 'isolation in the forcibly united collectivity' (1997: 36). ${ }^{1}$

Technology clearly plays an important role in any such negative characterisation of modern society, and Feenberg considers the Frankfurt School thesis 'dystopian'. Like Heidegger (another important source for Feenberg), Adorno and Horkheimer find technology implicated in the worst excesses of a social system based on quantification as the basis of strategies of control whose operations are inimical to meaning, even though the latter is clearly an essential dimension of human existence. However, Feenberg's main influence here is Herbert Marcuse, who was famously associated with the Frankfurt School and shared many of Adorno and Horkheimer's views on history, society and culture, but consistently differed from them politically. 
In the years after World War Two in particular, Marcuse argued that the negative image of modernity advanced by other Frankfurt School theorists was excessively pessimistic and in some ways a regression behind Marx, who had always emphasised capitalism's vulnerability to explosive social contradictions, as well as its facility for producing fresh strategies to maintain itself. Marcuse's optimism about the potential of the student movement, noted in the Introduction, contrasted markedly with Horkheimer's more pessimistic view, as did his more measured view of the Eastern bloc. In his One-Dimensional Man (1964) Marcuse presented an image of modern societies that was similar to the world of total administration depicted in Adorno and Horkheimer's work, but he also identified positive political potential in a new generation of young technologists, who he thought might be inclined to design technics for a better civilisation (1964: 227-229). This idea is an important launchingoff point for Feenberg's theory.

To develop this notion further, Feenberg engages with a third branch of scholarship, namely the constructivism associated with science and technology studies (STS), which came to prominence in the academy in the 1980s. Work in this school focused on the underdetermined character of technological artefacts, especially in their development phase (e.g. Bijker et al 1989). No strictly technical imperative leads from the discovery of wheels, pedals, handlebars, even pneumatic tyres, to what we know as the bicycle. Rather, the presence of such physical elements has to be parsed through the opinions and verbal behaviours of 'relevant social agents' for such an object to be produced. The meanings that shape technologies are social products, while the uses to which they are put emerge retrospectively: technologies and the problems they solve emerge in the course of the same social processes.

In constructivism Feenberg finds the opening he needs for critical theory to build on Marcuse's insight. If technology is not historically determinate but rather itself a dependent variable of the social process then it must be possible for human beings to influence its design. Constructivist studies of technology describe the social shaping of technology, showing how the beliefs and values of social groups affect the design of nascent technologies, especially in their development phase. Critical theorists had argued that technology framed modern society and culture, limiting the range of meaningful human experience. Marcuse's suggestion is that technical transformation might be the way to address these issues. Constructivism equips Feenberg with tools for the development of a political theory of technology applicable to the question of radical socialist transformation and thereby enables him to address the unresolved paradox in Marx's thought on the issue. Each of these sources, and the terms of Feenberg's engagement with them, is addressed in this chapter. 


\section{Feenberg's Marx}

Feenberg shares Marx's core conviction that, 'the goal of a good society should be to enable human beings to realize their potentialities to the fullest' (2002: 19). According to Marx, this society was coming within reach of humanity, largely as a result of the astonishing rate of development of productive power made possible in the nineteenth century by industrial technology. Industrial society was so wealthy that for the first time in history, universal human self-realisation was becoming a practical possibility.

Marx was one of the first philosophers to place technology at the centre of his understanding of the human condition. Many of his arguments, while controversial when he made them, have become almost common sense today. In particular, Marx was the first to suggest that the historical process rests centrally on the development of the productive forces. He famously argued that human experience, culture and civilisation turn not, as his contemporaries tended to argue, on providence or the unfolding of some spiritual purpose, but on the material practices that people engage in to produce and reproduce their material conditions of existence. Technology, or the means humans use to manipulate the world in order to extract what they need from it to survive and thrive, is central to this, and changes to technical capacity, in particular those that improve productivity, drive social change.

At the same time, Marx was also a critic of technology, especially nineteenth-century industrial machinery. He argued that in the capitalist organisation of production,

all means for the development of production undergo a dialectical inversion so that they become means of domination and exploitation of the producers. (1990: 799)

According to his theory of history, capitalism is a necessary phase of development that human societies must pass through if they are to reach the level of productivity required to sustain socialism. As this citation indicates, however, it is not a pleasant experience for most people because in this society only a small number of people enjoy the benefits of the new levels of productive power. For the majority, the new machines are a source of suffering, both physical and in terms of changes to social existence that correspond to the domination and exploitation Marx refers to here. Ultimately, though, Marx writes in the Grundrisse that the technology designed to dominate workers reduces necessary labour to a minimum and, for this reason, 'will redound to the benefit of emancipated labour and is the condition of its emancipation' (1981: 701).

In Capital, Marx describes the capitalist development of industrial technology as passing through two phases. The first ran roughly from 
the mid-seventeenth to the late eighteenth century and was based on the workshop. Workers who had formerly worked in their own homes using craft techniques and personalised implements found themselves reduced to the level of operating machines owned by capitalists. They lost their craft relation with the labour process, which they no longer controlled, and became deskilled. They also lost connection with the finished product, only engaging with the part of it that directly involved their efforts. Marx writes that this phase: 'converts the worker into a crippled monstrosity ... the individual himself is divided up, and transformed into the automatic motor of a detailed operation' (1990: 481).

With the spread of steam power in the early nineteenth century, however, a further change to the organisation of the factory occurs. Human workers cease to be the power source, and the various machines are hooked up into a single system, in which the worker's role is further diminished to providing 'supplementary assistance.' From this point on, machines constitute an 'automatic system' which grows 'spontaneously on a material basis ... adequate for it' (1990: 504). Workers become just a part of the industrial machine system; their activity is planned and imposed from outside by the mechanism. All parts of the process are subject to the same 'technical law' (1990: 465).

This development involves the emergence of a new form of authority, invested in the machinery itself. Marx's lifelong collaborator Friedrich Engels clarified the role of machinery in social domination in the following terms:

The automatic machinery of a big factory is much more despotic than the small capitalists who employ workers have ever been ... If man, by dint of his knowledge and inventive genius, has subdued the forces of nature, the latter avenge themselves on him, in so far as he employs them, to a veritable despotism independent of all social organisation. (Marx and Engels 1958: 637)

Technology here embodies social functions that are wider in their significance than merely enhancing productivity and efficiency. The machines are authoritative in the sense that they represent, to their human users and to society as whole, the only viable course of action. Their rise to power, so to speak, is a function of the fact that in order to maximise its productive capabilities the workplace must be tyrannised by the articulated, steam-powered system. The human consequences of these developments include further deskilling and reduction of workers' control over the production process, and their subordination to a new source of authority. These developments appear to the people involved as the inevitable consequence of new technology, as the price to be paid for its almost unimaginable expansion of productive power. 
When reflecting on its historical significance, Marx enthused about this development of the productive forces, arguing that for the first time in human history the species might reach a stage at which each individual could fulfil their potential. If the productive power of the industrial system could be freed from the constraints of having to produce for profit and instead be directed to producing to meet real human needs, he argued, then everyone would be free to devote their time to leisure and self-cultivation. The transition was deeply problematic, however, because of the multiple entanglements of technology and its liberating potential with existing society and culture.

Feenberg's critical theory of technology and his notion of technical politics are situated within this, Marx's problematic. Focusing particularly on what Marx has to say about technology, we are confronted with the problem, alluded to above, that Marx is both an enthusiast for technology, viewing it as carrying humanity forward to a superior form of social life, and deeply concerned about it as a force that diminishes the meaning of human activity while becoming a locus of domination exerting control over human actions. ${ }^{2}$

Focusing on Marx's critical comments on technology, Feenberg identifies three lines of argument, which he calls the design, process and product critiques (2002: 46-48). The design critique concerns the way that technology is constructed and shaped to serve particular social purposes. Feenberg cites Marx when he points out that 'it would be possible to write a whole history of the inventions made since 1830 for the sole purpose of supplying capital with weapons against working class revolt' (1990: 593). According to Marx, capitalists are motivated to produce technology that is harmful to workers in ways that underscore two further lines of critique. Machines are weapons against workers' combining to oppose and resist capitalists at the point of production, since they foster job insecurity. They are also introduced to reduce the cost of production, and this is commonly about reducing the wage bill by shedding employees and getting machinery to do the work instead. The resulting diminution of quality in the work process itself, as workers become mere 'assistants', is what Feenberg calls Marx's 'process critique.' ${ }^{3}$

The third, product critique is present wherever Marx criticises wasteful or foolish employments of technical means. This particularly concerns the production of commodities that correspond to artificial needs or even to things that are actually detrimental to human interests. An obvious target for the product critique might be the manufacture of weapons systems that are too powerful ever to be used, since this seems to be a misdirection of human technical capabilities. ${ }^{4}$ The category of artificial needs raises the question of what 'real' needs are and how they are to be defined. For now it is important to notice that the design critique of technology occupies a 
privileged position in relation to the other two. This is because it is only as designed that technology is harmful to humans, wasteful or otherwise damaging.

If Marx assigns explanatory priority to machines and implements it is not because they are completely exempt from being themselves socially shaped. There are numerous references in Marx's writings to social factors causing technology change to happen, even selecting specific technical designs. Describing the social changes that affected the cotton industry in eighteenth-century England, for instance, Marx writes that 'the revolution in cotton-spinning called forth the invention of the gin' (1990: 505). As Alan Wood (2004) points out, the fact that technology turns out to explain social change even when it comes after it in time is not as implausible as it sounds. ${ }^{5}$ It does raise the question, though, of its entanglement with other, supposedly more malleable social factors.

Notwithstanding this, and the comment Feenberg cites from Capital above, there is not much evidence in Marx's texts that he devoted any great critical energy to the social processes that shaped technology. Marx does not seem to see any paradox in his advocacy of technology as progress on one side and his critique of technology as regressive under capitalism on the other. His references to 'dialectical inversion' and 'redounding' in the sections cited above are masks on a potentially thorny question that he did not address directly. ${ }^{6}$ Feenberg's project of developing a politics of technology design, or technical politics, is an attempt to make sense of this issue.

\section{Sources of critique}

If technology design is a dimension of the transition to a superior form of social life then Feenberg's challenge in his critical theory of technology is to deepen the critical perspective on technology while maintaining a belief in science and in technology as basically progressive. He needs to clarify what is wrong with capitalist technology in a way that is sufficiently profound and comports in particular with the critical explanation of modernity, while at the same time leaving a way open to changing it and preserving the basic Marxist belief in technology's potential to be a force for human emancipation. To achieve this, he clarifies what is wrong with modern technology by drawing on insights from earlier thinkers both within and outside the Marxist tradition. Of particular importance here are the Frankfurt School critical theorists, who examined the implications of Marx's core historical and economic propositions for twentieth-century culture. Simply put, Feenberg tries to use their ideas without lapsing into their stark condemnation of modern technology. 
Critical theory elaborates on three aspects of Marx that are of particular importance to Feenberg's project. First, it builds on Marx and Engels' argument, discussed above, about the relationship between technology and authority, showing that in capitalist modernity the two are linked through a mediating concept of social rationality. In the works of Adorno, Horkheimer and Marcuse, instrumental reason is the force that shapes the modern experience of the world. The Frankfurt School authors present a critique of modern science as the application of this kind of reasoning to the understanding of nature and the physical universe. They complain that this conceals or obscures aspects of the world and of experience that elude its in-built orientation towards measurement and regularity.

This line of argument builds on Marx's discussion of the sensory configuration of the human creature and its modification over the course of the historical process. In early writings Marx described the 'sheer estrangement' in bourgeois society of all human senses in 'the sense of having' (1981: 94). In the rationalised version of capitalism, humans are geared up, so to speak, to relate narrowly to objects in the world in terms of what they can be used for or how they may be consumed, with a corresponding neglect of the full range of their potentialities. Underlying this perspective is the idea of a distortion of human and technical potentials as a result of what Feenberg calls 'formal rationality. ${ }^{8}$ The source for this idea is not Marx but Georg Lukàcs.

Lukàcs's version of Marxism, as formulated in his 1923 (1981) classic History and Class Consciousness, describes Marx's philosophy as 'the theory of totality'. On his reading of Marx, the standpoint of the proletariat is unique because, while throughout history people who work have created social reality, industrial workers are the first group of such people who might become fully aware of their role and its implications. Whereas previous labouring classes have been in various ways fragmented and held apart by different social structures, in industrial capitalism their ontological role as creators is matched by their potential epistemic one as socially omniscient. Because workers are thrown together in a largely homogeneous social mass, sharing key experiences and a common culture, the working class are in a position to comprehend both the world they have created and their role in creating it. Thus, their self-emancipation is almost inevitable once they have access to the truth: why should they continue to produce enormous wealth, only for it to be appropriated by the bosses?

The main obstacle to proletarian self-emancipation, elaborated in Lukàcs's account, is reification. This idea builds on Marx's account of fetishism in Capital, according to which the extraction of value in commodity production results in a strange inversion whereby objects that are produced for sale on the market become charged with a special liveliness, 
while the people whose labour produced them are exhausted and spent, coming to seem in their own eyes lifeless and inert. In reification the agents of history perceive themselves as incapable of effecting real change yet perceive their own collective products as vitally fascinating. Lukàcs generalises this analysis onto the whole of modern culture, arguing that reification is the central problem of modernity, resulting in the pervasive belief that the world is made up of causally interrelated objects whose logic overrides subjective considerations of quality, meaning and value. ${ }^{9}$

Lukàcs's work was the focus of Feenberg's first monograph study (his 1981) and these ideas are central to the critical theory of technology. In that work Feenberg suggests that the most questionable element in Lukàcs's theory is also his 'most original and fruitful' point, namely 'the discovery that linking all the phenomena of capitalist society Marx criticises, from fetishism to mechanisation and crises, there is a common structure, a pattern constituted by the imposition of formal rationality on the social world' (1981: 76). Reification is a distorted perception of the world, then, that runs through modern science and culture and fosters a disposition to identify an instrumental pattern and connection between facts as the hallmark of a realistic understanding of the natural world and human social processes alike. ${ }^{10}$

Lukàcs's idea of a distinctively instrumental reason as shaping modern experience is taken up by and becomes one of the unifying themes of Frankfurt School critical theory, uniting Adorno and Marcuse. ${ }^{11}$ Instrumental or means-end reasoning is said to underpin modern science and to be implemented in the technology associated with it. Centrally, then, science purports to show the world as structured according to laws of causation that describe behavioural regularities. Science as such is true, in the sense that it consists, as Karl Popper (1989) would have it, in the open-ended refinement of propositions that are formulated to ensure they are falsifiable in principle. However, for Frankfurt School theorists the endless accumulation of yet-to-be-falsified statements that makes up scientific knowledge misses something deep as a result of a flaw in its fundamental orientation to the world.

Scientific reasoning works from the assumption that there is a knowing subject and an external world of objects. Taking this distinction as fundamental, it concentrates attention on the subjective image of the outer world and, by controlling experience through the construction of experiments and tests, seeks to refine that image by eliminating fallacies, misconceptions and falsehoods (these may originate in such things as deficiencies of reasoning, failures of language or lack of evidence). But what if the premise - of a discrete, knowing subject and an opaque object - is itself wrong? Critical theory prefers to start by acknowledging that the subject is itself a part of nature; that the boundary between it and the outer world has a history, was produced. This history is part 
biological, to be sure, but is also shot through with social and cultural events and transformations. The appearance of an epistemic subject is itself one of these events, and it is no coincidence that it emerged at the same historical point (in the seventeenth century) as the 'acquisitive individuals' of bourgeois political theory (MacPherson 1962).

For Adorno, there is a basic tension between the success of science, especially its privileged form of rationality - deductive logic - and our more fundamental, intuitive sense of the world and our place in it. This tension is most clearly manifest in the continued existence of art as a social institution, which long since ceased to be based on standards of accuracy in representation (if it ever was) and presents images and experiences that are constitutively resistant to logical analysis. Art is a revealing anomaly in a thoroughly rationalised world. For Adorno - and indeed something similar obtains in Heidegger's reflections on poetry $(2014)^{12}$ - its continued existence and the fact that humans still seem to need it is suggestive of a fundamental dislocation within the spirit of modern life. Adorno maintains that what people get from art is reflection on and reaction against enforced identity, the subject-object split at the heart of modern science and technology.

This relates to Marx's reflections on the experiential impoverishment of workers in capitalist society. In his 1844 manuscripts Marx bemoans the distorted development of the human senses, which become focused on owning things, while his later work highlights the brutalisation of human sensibilities in industrial labour. These developments have implications for the relationship of the species to the truth. Discerning a distinctive but largely implicit (unelaborated) epistemology here, Feenberg writes that Marx appears to be advocating 'a unique form of phenomenalism' (1981: 219). This is the basis upon which Feenberg advances an aesthetic dimension to his own critique of modernity and especially modern technology.

In Feenberg's work the critique of scientific or instrumental reason in the Frankfurt School becomes the wry observation that scientific laws are 'always subtly eccentric with respect to the real' (1981: 274). He maintains that the goal of revolutionary politics is to change society, in its most basic definition of reality, in its paradigm of rationality, in its founding practices' (1981: 196), and he even claims that, 'Marx founds a new concept of reason in revolution through an ontological treatment of social categories' (1981: 2-3; emphasis in original text). But even as he mines Marx for an implicit alternative epistemology, he redirects the efforts of critical theory away from a direct challenge to science or instrumental methods of analysis.

Feenberg also attempts to move beyond the principle of nonidentity as the ground of critique. His inspiration for this is Marcuse. In One-Dimensional Man (1964) Marcuse argues that, rather than 
having recourse to high art, ${ }^{13}$ it is possible to envisage a more political response to the rationalised cultural conditions described by critical theory. Paradoxically, this might even be made possible by developments within the sphere of technology itself. Marcuse provides a glimpse of a less dystopian perspective on technology when he entertains the possibility that a new direction for technical development (1964: 227-229) might arise immanently to the sphere of technology design, resulting in technics guided by freely chosen human ends and informed by aesthetic values (1964: 239-240). He speculates that a new generation of technicians might create a less rationalised way of life not by renouncing technical reason but by putting a distinctive twist on it. The technics of the future might then comport with more liberated, experimental forms of social life. As Feenberg puts it, 'Marcuse elaborated a positive theory of liberated technical practice' (1981: 250).

Feenberg finds philosophical significance in Marcuse's vision, arguing that it shows that non-identity is merely a negative principle which says only that science as it is now is not the whole truth while interpreting art as the sign of an insuperable absence, namely the missing reconciliation of humans with inner and outer nature. In his early work, Feenberg argues that Marcuse envisaged something more positive, namely the active reconciliation of subject and object based on alternative technology:

Here the Frankfurt School's insistence on non-identity is superseded by a different kind of identity, the identity of nature in subject and object, which recognises itself in reflection and aesthetic appreciation and mediates itself in a positing that affirms rather than transforms what is. (1981: 252)

This is an important passage because it highlights the fact that Feenberg skates close to the embrace of an ontological critique of capitalist modernity to be implemented, as it were, through a utopian technics of reconciliation. Critical theory's attachment to non-identity as the only residue of meaningful resistance is here replaced by an organicist holism that affirms nature as the common basis in reality of subject and object. In declaring that his theory warrants a consciousness that affirms rather than resists identity and seeks a new, higher unity to be established on alternative technical foundations, Feenberg also theorises a political space within technology design, rather than denouncing technology as simply the agent of instrumentalism. This is the space of technical politics.

While the influence of Marcuse is clear in this discussion, it would be quite wrong to read Feenberg as simply recycling the ideas of an earlier generation of theorists. In particular, while he retains a critical focus on modes of rationality and the entanglements of scientific discourse in questions of social power, his critique of technology does not involve the challenge to science, or the imputation of limits to the reach of science, 
that is common to Adorno and Heidegger. Feenberg detaches radical critique of technology from the question of whether science itself is biased. He writes that 'we need not await the reform of science to reform technological design' (2002: 28). This suggests that the nature he affirms in his vision of a future society is the same one that is studied by contemporary science. Feenberg is in this respect more philosophically conservative than earlier critical theorists but more politically radical: he drops the critique of identity-based epistemology but argues for the possibility of some kind of willed transformation of technology, which would be the solution to Marx's paradox.

\section{Ambivalence}

Feenberg's concept of ambivalence is intended to grasp the fact that the critical theory of technology sits between broad questions concerning the character of a civilisation and specific ones concerning how things get done. Culture, he says, is embedded in technology, which it needs to survive and to sustain itself as such, while technology is profoundly rooted in culture, from which it takes its challenges and problems. In this way, culture sets what he calls the horizon on technology while technology is a powerful determinant on social power relations within a culture. The web of dependencies here is central to Feenberg's dialectic, which can be represented diagrammatically as shown in Figure 1.

For Feenberg, the ambivalence of technology consists in the fact that on one side it is a feature of daily life and as such routinely modified, contested and argued over with regard to specific things that it does: solving or causing a problem, making a process more efficient, excluding some users, etc. On the other side, technology is closely bound up with the image people have of their society, even the civilisation of which they are members. The notions of 'post-industrial' or 'informational' society are used in a fairly routine way, for instance, and they suggest a mental map of the world that is coloured by a sense of technologies in their specific differences from others (this is explicit in the designation 'post-industrial', but implicit in the reference to IT, as against older machinery, in 'informational society').

Feenberg's argument is that in 'our modern society in which devices form a near total environment' (2002: 17), everyday activities with technology touch upon the meaning of civilisation itself. Technology is shaped and moulded by social actors with competing and sometimes conflicting demands. When technology changes and new artefacts come into use, this feeds back into practice, changing the actors along with their requirements and expectations. Each such iteration, or twist in the socio-technical entwinement reflects a modification to the meaning of 


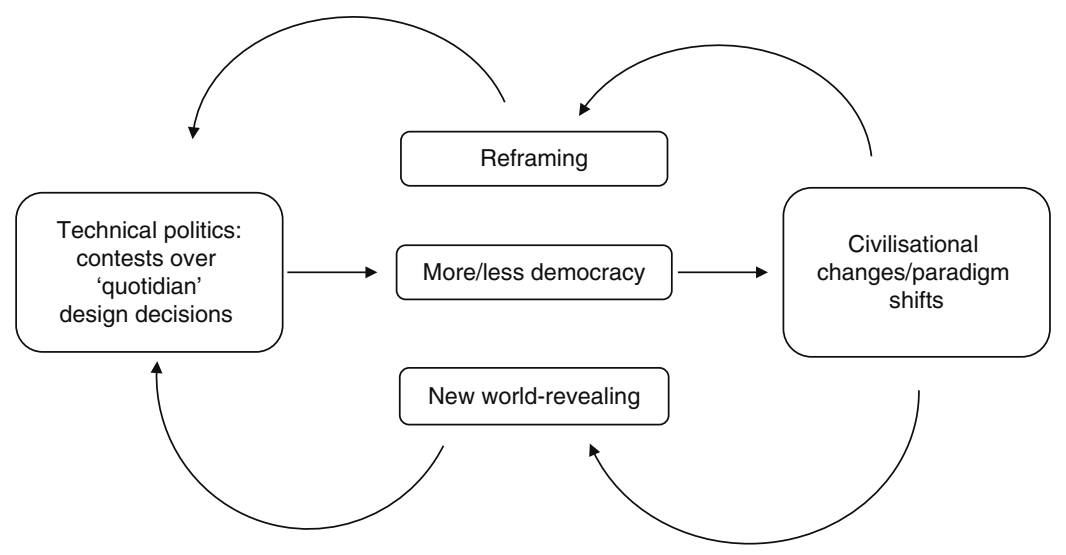

Figure 1 Feenberg's dialectic of technology

technology and, therefore, life itself. In a technical civilisation, or one that thinks of itself in those terms, these issues are mediated differently than in other societies.

The meaning of 'technology' in a society that has more mobile phones than humans is different than it was in one where most peoples' experience of devices was the machinery they operated in the factory where they worked. ${ }^{14}$ Less obviously perhaps, this has implications for how people imagine the social world, including its possibilities, which Feenberg calls 'potential', and the limitations set by society on what counts as 'realistic'. A clear illustration of this point is the way that the use of social media has changed the meaning of 'society', raising hopes and fears in ways that scholars are still struggling to come to terms with.

There is a second dimension to Feenberg's dialectic, however, which goes beyond the reflexive implications of new technologies for the meanings of old concepts. His argument is that the principled basis of social disputes over the meanings of specific devices also affects the cultural practices internal to technology development. In industrial society, he says, technology developed in a way that was largely autonomous, beyond the control of day-to-day struggles and contests. Large corporations and government research institutes controlled how technology was developed, with no interruptions from interested parties, citizen activists or non-expert groups. The result was a society that was largely deferential to the authority of technology and to its associated experts. This technocratic system was the dystopian social image targeted by the earlier generation of critical theorists discussed in the previous section.

Feenberg's suggestion is that this part of the dialectic of technology development is changing. As people take a more active role in questioning 
technology design and even start to demand technologies that serve their interests rather than just those of powerful organisations and elites, so this has altered the way that they think about both technology and society. In this way, he says, the horizon on technology development - the kinds of things people expect technology to do and the ways in which they imagine it will do them - is being modified. Potentially, more democracy in the design of technology could bring about a wider, civilisational shift.

Iain Thomson, in his essay 'Feenberg's technical politics: between substantivism and constructivism', identifies a tension in Feenberg's theory at this point. He writes: 'the crucial question is: can ontic political decisions and resistance of the type Feenberg puts his faith in ever affect the kind of ontological change Heidegger seeks?' (in Veak 2006: 60). This question is central to any assessment of the success or failure of Feenberg's project, and therefore it is a central theme of the current work. Feenberg's view is that, viewed in ontic terms, modern technology is 'a human and environmental disaster' (2002: 9). 'Modern technology', he writes, 'embodies the values of a particular industrial civilization and especially those of elites that rest their claim to hegemony on technical mastery' (2002: v). However, he doesn't trace the negative impacts of technology to modern technology's 'essence', as Heidegger does, but rather to its place in an ensemble of social and political relations. ${ }^{15}$

The problems posed by technology are in many ways cataclysmic, which sometimes leads Feenberg to write as if his theory participated in Heideggerian paranoia about the loss of a world, but his understanding of these problems and of technology's role in them is consistently political, ontic rather than ontological. Feenberg is explicit in saying that this position gives him access to the polemical and other features of what is known as a 'substantivist' critique of technology while maintaining a strictly social constructivist position. On this basis he consistently advocates a politicised constructivism, within which democracy is presented as the solution. When dealing with the threats technology poses, he writes:

The remedy is therefore not to be found in spiritual renewal but in a democratic advance. That advance implies a radical reconstruction of the technical basis of modern societies. (2002: 13-14)

Whether this argument succeeds depends in part on the extent to which Feenberg's reliance on characterising technology in terms of a distinctive rationality can really be distinguished from substantivist notions of enframing and a narrowing of worldview. It also turns on whether a constructivist, political grasp of technology as socially shaped can comprehend the kind of cultural and civilisational consequences that Feenberg's critical theory highlights and purports to offer a way of changing. Finally, it depends crucially on whether democratisation and what he calls 'reaestheticisation' in the sphere of technology design can bear the large 
historical weight - of accounting for civilisational change - that Feenberg chooses to rest on them. These questions are central to the discussion that follows in later chapters of this book.

\section{Technical reason}

Feenberg sometimes freights technology with the kind of negative significance assigned to it by earlier critical theorists and 'substantivist' philosophers of technology. At the same time, though, he maintains that the central concepts in his version of this negative characterisation are in fact ambivalent and reflect social determination, not conditioning by an unchanging essence of technology. This preserves a space in which technology might be contested and its design altered so as to facilitate a different kind of technical civilisation.

To clarify this, he introduces a key distinction between technical reason, which is present in any instance of technology regardless of context, and what he calls 'technological rationality', which is specific to capitalist modernity and indeed hegemonic in that social formation. The thoroughgoing imbrication of these two - indeed, they are inseparable in practice - is what led the earlier generation of thinkers to view technology as irretrievably implicated in the dark side of modernity. In contrast, Feenberg maintains that technical reason might be liberated from its current entanglement in the socially dominant form of rationality and occupy a more benign place in an alternative constellation.

Calling technological rationality 'hegemonic' means that it is the dominant way of doing things and that it is so because it is perceived as objectively the right and 'neutral' way to solve problems. It is as a manifestation of technological rationality that technology is authoritative. ${ }^{16}$ Technology as such is produced and sustained (in use) through a reciprocal interplay of technical solutions (devices and designs that work) and the prevailing conception of technology (as authoritative). There is circularity here: because technology 'works' it is seen as beyond question, and because it is authoritative it gets introduced into more situations, where it works.

Constructivist scholars have demonstrated that the idea of technology 'working' is not as straightforward as it might seem. Their fables, which usually describe the early development of specific technologies, demonstrate that the pattern in technology development is not the common sense one of a problem encountered and solved by a designed solution. Much more often, technology gets introduced to a pre-existing situation with a degree of indeterminacy about what it is 'for'. Once it starts to operate then people discover how it 'works', in the sense that they learn how to operate it but also in the more surprising one that they learn its 
capabilities and advantages and then restructure their practices around it, to extract some unanticipated (or barely glimpsed) benefit. As Feenberg puts it, 'clarity on these matters is often the outcome rather than the presupposition of technical development' (2001: 79). A very clear illustration of this would be the home or personal computer of the 1980s, which, as Feenberg points out, was 'launched on the market with infinite promise and no applications' (2001: 85).

Technology, then, always appears to be the 'obvious solution' once it is present in a situation, and this is a key part of its peculiar authority. Machinery enters the workplace and is accepted because it is machinery in Feenberg's terms, it is 'codified' as such. Luddism - refusing to accept technology, or resisting the machines - has become the very paradigm of irrationality or eccentricity. Technological rationality is a codification of technical artefacts, which ensures that once they are in place in a given situation they reproduce the dominant structure of power. Technology both destabilises prior arrangements, since it imposes a change in what people do, and re-enforces social power relations to ensure that the new situation that emerges reproduces and extends the hold of dominant interests.

This seems very one-sided for a theory of ambivalence, but Feenberg's metaphor of codification brings something to the situation that is absent when technology is conceived only as a mode of rationality, or ontologically as enframing the world. Codes are flexible: they can be interpreted and reinterpreted, and they can be turned around and used to make new programs, or 'inscriptions. ${ }^{17}$ If technical reason, the efficacious core of any given technology, is the key stake in the game, conditioning its employment and use, the moves in this game concern the details of design - that is, how that core of capabilities gets articulated to practical purposes, serving specific social interests in concrete situations. The meaning of ambivalence, therefore, is that while technology always advances social domination, it also tends to proliferate openings for people to exploit, through which they can resist power and extract unintended benefits for themselves.

Feenberg does not conceive reformed technology in terms of a different world-revealing, which would be the ontological conception of civilisation change, but rather anticipates that multiple, local contests for control over the meanings of different technological capacities will add up to a shift in the meaning of technology as a whole. Such a change would of necessity be part of a wider change to the way that people conceive the social world and their place in it, and, as discussed above, for Feenberg technology would be central to this. As part of this transformation, technology might lose its authoritative character and its association with dominant social interests, though this is not a possibility Feenberg ever entertains. Taken together, these changes might herald 
what substantivists would understand as an alternative world-revealing, but, unlike his critical theory forebears, Feenberg is not focused on this aspect and it is not one of his objectives to set out a theory that comprehends civilisation change in those terms.

One strength of his theory is precisely that it considers technology and the question of technology design independently of ideas about science. Treating technology as autonomous of science saves Feenberg from the charge of prevarication between substantivism and constructivism. His disavowal of the critique of physical and natural sciences, which contrasts with his view of the human sciences ${ }^{18}$ means that the question of alternative modes of world-revealing is, at the very least, deferred. Technology reform may ultimately issue in a change of civilisational paradigm, but the implications of this for how humans relate to and understand nature are a function of technical politics and not the other way around. In this sense Feenberg is firmly on the side of constructivists, who limit their analyses to accounts of proximal factors shaping this or that individual technology design. His focus is not on deepening such accounts in the direction of their implications for ontology but rather in broadening them to include an account of their political significance.

As stated in the Introduction, Feenberg's engagement with constructivism was decisive in the development of his theory. Constructivist scholars provide detailed historical accounts of the social shaping of technical artefacts. They show how the competing interests of different social actors at the scene of invention and in the various phases of product development are manifest in (sometimes opposed or conflicting) descriptions. These latter are more or less determinate in their consequences for the resulting artefacts, depending on the support they get from wider social constituencies. For some people, bicycles were 'safety' bicycles, while others sought the more excitingly named 'bone shakers', and it was a social conflict or competition between these social groups that finally shaped the modern bike, rather than any narrow technical considerations (Bijker et al 1989).

A widely acknowledged failing of constructivist work is that while these narratives disclose the importance of social actions and actors in making technologies what they are, they do so largely in abstraction from questions of social power or politics (Winner 1993). Constructivist studies in STS effectively relativise the whole question of what technology is to its social co-ordinates, highlighting the role of motivated human choices above all other factors in the shaping of artefacts. The focus is on a specific 'semiotic hinge' (Bijker 1997: 197), where words and meanings from limited practical contexts get folded into the specifications for a 'good' tool. This is a strangely decontextualised approach to language and design communities, which almost always brackets out wider sociological questions about the class background of participants and historical ones 
regarding the wider cultural context and how its meanings limit and condition more proximal actors' choices.

However, for Feenberg, constructivism puts a helpful spotlight on the role of human agency in technology design. Technology is not determined by science or by standards that are technical 'in-themselves'. Rather, constructivists show that technical choices are 'underdetermined' by such considerations: whenever any two technologists disagree over a design decision then social factors are in play. The constructivist scholar pores over diaries and notebooks to identify what they were and to chart the social 'causes' that inform each step (e.g. Bijker 1997). But while they identify 'the social' as the shaping force, they tend to overlook its contradictory and conflicted nature, with the result that their narratives, while sometimes replete with surprising insights pertinent to the history of specific artefacts, lack critical force or purchase on the wider entanglements of technological designs.

Feenberg agrees with the basic constructivist insight that 'many paths lead out from the first forms of a new technology' and that 'there are always viable technical alternatives that might have been developed in place of the successful one' (2001: 10). However, he politicises constructivism by observing that the social context itself contains contradictions and that, beyond the narrow set of group-specific rival interpretations that tend to manifest in laboratory disputes, social power is a factor in overdetermining design. On this basis, Feenberg concludes that 'The evolution of technology can no longer be regarded as an autonomous process but must be rooted in interests and social forces' (2002: 49). His main innovation in relation to constructivism consists in his understanding of those forces in terms of a theory of their historical and political significance.

By articulating the constructivist insight that the notion of 'working' technology is a product of multiple social determinations to the Marxian critique of technology design as shaped by class interests, Feenberg radically alters the significance of constructivism. The point then becomes not that inefficient technology might be 'equally as good' as efficient technology, whatever that might mean, but that efficiency itself is a socially contested notion, and one that is an important stake in many of the wider social disputes that shape technology development.

Feenberg (2003) explains what he means by this in an analysis of exploding boilers on nineteenth-century steamships. Company owners favoured boilers made with thinner outer skins because, using less metal, they were cheaper to make. However, these boilers were dangerous, as they tended to explode when pressure levels were high for extended periods of time. The explosions killed workers and cost the company money. Overall, though, in the eyes of the companies it was more efficient to continue using exploding boilers than to spend the extra money on safe ones. From their point of view, efficiency equated to short-term profitability. 
Trades unions countered the idea that exploding boilers were best not by demanding less efficient machinery but by insisting that not blowing up workers should be part of the meaning of 'efficiency': machinery that occasionally kills its operatives cannot be considered efficient, even if it is more profitable.

Using this and other examples, Feenberg extends the constructivist insight that technology is technically underdetermined into controversies and discussions that are inherently political, rather than merely generating intriguing little tales that narrate the emergence of this or that device. In this way constructivism becomes a methodological first principle for technical politics. Feenberg argues that in recent decades there has been increased willingness among widening groups of people to engage in disputes about how technology should be used, including what the best and most efficient employment of it might be. Constructivism shows how social processes like this can alter technology design, focusing particularly on how rival social groups use language to shape technology to their ends by advancing descriptions that reflect the interest they take in it. This corresponds to Feenberg's notion of a technical code that can be reworked.

To develop the idea that disputes over the way technology is described should be understood as a struggle for control of its code, Feenberg draws on Michel Foucault's theory of discourse. Foucault's studies of madness (1985) and medicine (1986) showed that bodies of scientific knowledge are both reliable representations of social reality and inscribed in practices that produce the world they describe. Psychiatry is both objective knowledge regarding mental illness and, as discourse, itself an objective structure that works through institutions and practices to sort the world into fixed categorical orderings (sane/insane; well/unwell). These categories are both true, in the sense that phenomena are pulled together under them in a way that 'works', and shot through with social power: the insane and the sick are silenced and assigned a passive place within the institutional order while experts are given rights and entitlements to dispose over them.

Viewing technology as a mode of discourse enables Feenberg to extend the application of Foucault's thesis of an intimate alignment of knowledge and power. His argument casts technology as a structural component of modern societies aligned to the aforementioned discourses and practices. Like language, or discourse, technology is a material force in the world and an agent of the imposition of a particular rationality. Coming to terms with this, as the example of Luddism shows, involves internalising certain norms and complying with the rules that flow from them - not breaking the machines, following the instructions, etc. This reckoning with the authority of the machine is part of becoming a normalised subject rather than a deviant one. As Feenberg puts it, 'the condensation of 
social and technical determinations tends more and more to appear as the very definition of rationality' (2002: 67).

According to Foucault, reason itself is produced through these discursive codifications: rational subjects are defined by their avoidance of behaviour that has been labelled 'mad'. Being rational does not entail adherence to the rigorous procedures of logic - 'mad' people are often quite good at that - it means having the code work its way through one's body to produce a particular kind of interface with the wider social world. Those whose bodies do not accept the code find themselves on the wrong side of the lines drawn by discourse and become objects rather than subjects of discourse. As such they are effectively deprived of language as a resource for making sense of experience. Foucault's avowed aim in his famous book about madness was to reinscribe 'mad' people's experience in the historical record and in this sense to let unreason speak.

Some Foucault scholarship has highlighted the similarity between his thought and that of Heidegger (Eribon 2011: 85; Han 1998: 12). Both identify objective scientific-technical institutions and structures with a particular worldview that is associated with domination. For Foucault this is the modern episteme; for Heidegger it is Western metaphysics. Both thinkers highlight the role of reason and rationality as promoting a practice of sense-making that is exclusionary: Foucault writes of the 'rarefaction' of discourse (Foucault 1981: 58), the way that it excludes prohibited, illicit formulations and ways of speaking about and interacting with the world that are considered unacceptable by power. Similarly, perhaps, Heidegger writes that the essence of modern technology is nothing technological but is rather a 'world-revealing' that only discloses raw material to be used, excluding other ways of being.

Feenberg draws on Foucault, however, primarily as a critical theorist of rationality. ${ }^{19}$ His interest is not in highlighting an 'other' of technological reason which might correspond to the utopian technologies of the future, but rather in another aspect of Foucault's critique, namely his thesis that there is no power without resistance. Whereas Heidegger's critique of modern rationality leads to a search for poetic language to articulate the fundamental homelessness of modern humans in a world fashioned by instrumental reason and domination, Foucault shows that the order of discourse can only produce a normalised subject because it (discourse) always encounters resistance. No one is completely normal: everyone dabbles in madness, often positively framing it as 'character' or 'personality'. In the interstices of a legislated normality the more fundamental condition is strangeness, difference. ${ }^{20}$

Feenberg argues that such difference tends also to emerge in human relations with technology. This means that, viewed as the inscription of the correct way to use any given device, the technical code is 
only efficacious because it runs up against a buffer, namely the human element. This element is, of course, compliant; the program compiles and runs in the sense that human beings use the technology effectively. At the same time, however, they resist, not by smashing the machines (they aren't 'insane') but by exploring possibilities and capacities within the devices. Gamers modify game code, for example, to unlock or even to create 'cheats', patients' groups circumvent safety regimes to claim an active role in drug trials, unemployed people use hacked software to game government 'job-seeking systems' and so on.

Drawing on Michel de Certeau's (1984) distinction between strategy and tactics, Feenberg writes that the strategic standpoint of managers implementing technology 'privileges considerations of control and efficiency' (2002: 16), while the tactical standpoint of the managed is 'far richer.' Tactical operations on the part of multitudinous subjects are grounded in the 'everyday life-world of a modern society in which devices form a nearly total environment' (2002: 17) and create openings in technology design. These diverse, widely diffuse practices of resistance centred on the contextual meanings of technology are challenges to the authority of technologists, managers and technology itself. For Feenberg they add an indispensable dimension to the extension of democracy envisaged in the Marxist critique of capitalism.

\section{Technology and socialist transition}

When Feenberg writes that 'under socialism, workers ... can change the very nature of technology' (2002: 53), he envisages not a wholesale, allat-once transformation in what we mean by 'technology' but rather a series of changes to tool and machinery design which, taken in aggregate, will amount to a drastic overhaul of the material infrastructure of society and of the human relationship to that infrastructure and the world beyond it. Under socialism, thinking technically will carry with it a set of different connotations than those that come to mind at present. If capitalist technology symbolises efficiency, authority and enhanced control, socialist techniques will be disposed towards the solving of human problems, greater care for the environment and the qualitative enhancement of human experience. Feenberg's vision is firmly focused on political change and the place of technology in securing and implementing that change, with the issue of fundamental world-relations, including a less instrumental relationship with nature, a more distant concern.

Feenberg upholds the constructivist principle that technology is only as it is codified and not anything 'in-itself'. Hence, the codification can be changed, pushing technology into new forms and, potentially at least, a different place in the social imaginary. As part of this development, 
the material reality of technology will be affected so that designs will bear the impress of a different cultural reality, and this in turn will alter the prevailing idea of what technology is or can be, and of what natural reality is like and how it should be approached. This way of construing things frustrates Thomson and leads him, in the above-mentioned critical essay, to view Feenberg as caught between essentialism and constructivism. Thomson's critique misses the mark, but it highlights the problem that politics is a multi-layered practice operative across more than one temporal register. Workplace arguments over the most efficient use of e-mail, for example, are at several steps' remove from more longstanding conventions and codifications that condition what technology is and can be. At times, in his development of technical politics, Feenberg conflates these two levels of analysis.

This enables him to suggest that principled interventions in technology design - in favour of designs that broaden participation, against those that deskill or dehumanise workers, for instance - obviously comport with a wider shift in the technological imaginary, or the place people assign to technology in their mental model of society. This is an intriguing claim, on which much else in Feenberg's theory rests, but it also raises many questions, which, as we will see later, he doesn't address. It must be acknowledged that there is a kind of evasion here when it comes to discussing and classifying actual technologies in terms of the political dramaturgy that underpins Feenberg's thesis. How much of the discussion around any given technology is susceptible to analysis in terms of its democratic or aesthetic principles? Moreover, the notion that functioning artefacts are thoroughly shaped by such concerns seems to assume that they (the artefacts) have nothing to say about their role in the situations in which they operate.

Feenberg envisages a technical politics in which people enthuse about and participate in technologies and technical decisions without direct reference to wider ontological issues. His conviction is that in making design more democratic and in opening it up to aesthetic values that humanise technology, it will be improved. Feenberg writes that in a socialist society, 'reconstruction would not be determined by immanent laws of technological development but on the contrary by social and political choices' (2002: 51). His argument is that these choices can be determinate for technology design and that the outcome of democratic design will be a change of civilisational model. The idea of technical politics connects these two things and is what enables Feenberg to evade the charge of prevarication levelled at him by Thomson. Feenberg is determinedly not an essentialist, but whether he succeeds in building a bridge between the ontic and ontological levels depends on your assessment of the overall success of his theory.

The vision of broad societal transformation effected by politicised technology development is informed by the affirmative principle that 
a better world is possible and the belief that technology design is an important, perhaps the most important, part of how that world can be created. This attitude includes openness to, perhaps even faith in, the idea of a technological event that might produce the kind of global perspective shift required to take us into a new civilisation. There is, though, no account in Feenberg's theory of how such an event might be willed into existence. Feenberg is not asking us to start imagining new technologies for a new world. The technology he affirms is the technology that is here now, among us. His theory reflects the fact that people seem to be engaging with that, arguing about it and changing it in ways that were unthinkable just a few decades ago. There is no 'essence' of technology to contend with and, even if there were, his technical politics does not go there. Technical politics involves challenging bias in existing technology designs. Feenberg's theory targets the underlying logics that produce such bias and identifies openings for the development of alternative design principles, including aesthetic values, which might inform the development of an alternative technology for a better civilisation. These themes are the focus of the next four chapters.

\section{Notes}

1 They write that 'today machinery disables men even as it nurtures them' (Adorno and Horkheimer 1997: 37).

2 Marx writes, for example, that the dreadful conditions in nineteenth-century garment factories were 'nurtured by the very nature of the sewing machine' and says that the 'fearful increase in death from starvation during the past ten years in London runs in parallel with the extension of machine sewing' (1990: 601, 603).

3 There is disagreement in the literature over the ways in which this might matter. For those who focus on Marx's later writings, the diminution of the quality of the labour process under capitalism will be offset by a reduction in the quantity of labour undertaken in socialism. Everyone will have to do a little bit of unpleasant work, but the real focus of life will be leisure time. For interpreters who are more influenced by Marx's early works, especially the 1844 Manuscripts, the realm of 'all-round development' entails a qualitative shift in the character of work so that it becomes, as Marx put it in one of his later texts, 'life's prime want' (1978: 18). It is obviously harder to reconcile that view with the notion that communism inherits its technical foundation from capitalism.

4. Marx writes that 'the field of application for machinery would ... be entirely different in a communist society from what it is in bourgeois society' (1990: 515 fn 33).

5 Hysteresis is, or can be, a feature of functional explanations. Cohen (1978) and Elster (1986) discuss the implications of this for social explanation, reaching opposed conclusions. 
6 Marx's failure to address the question is largely reproduced in recent scholarly literature. For example, David Harvey, in his commentary on Capital, touches on the paradox discussed here but then defers serious reflection on it, writing only that 'a socialist revolutionary project in the long term cannot ... avoid the question of the definition of an alternative technological basis' (2010: 219; my emphasis).

7 The abolition of private property would lead to the 'emancipation of all human senses and qualities', presumably meaning that the world would feel different to liberated humans (1981: 94).

8 This designation is not, of course, original to Feenberg - but he gives it a new priority, as will be explored further in the next chapter.

9 For Lukàcs, the solution lies in revolutionary praxis oriented to breaking down the twin illusions of the vivacity of things and the passivity of people in the process of building a revolutionary party.

10 Applied to technology, Lukàcs's concept of reification bears strong resemblance to Martin Heidegger's notion of enframing. As Lucien Goldmann pointed out (1977), Lukàcs formulated his ideas some decades earlier and was almost certainly an unacknowledged influence on Heidegger's thinking.

11 One of the aims of the current book is to correct Feenberg's pro-Marcuse bias and to show that on certain key points Adorno is a more useful ally to the critical theory of technology.

12 Heidegger (2013, chapter 1) targets a sense that something is missing from modern experience which can be addressed not directly from within that experience but only allusively, using poetic language. The continued hold of poetry on moderns, who are taught from a young age to favour practical and effective modes of action, speaks to the sense of something profound being overlooked.

13 According to Adorno and Horkheimer, 'With the progress of Enlightenment, only authentic works of art were able to avoid the mere imitation of that which already is' (1997: 18) - that is, to escape the logic of equivalence and exchange.

14. Feenberg refers to 'an earlier consensus' that 'brooked no interference with the decisions of technical experts' and contrasts this with the 'increasing weight of pubic actors in technological development' (2002: 24). The latter seems to occur with the rise of digital technologies but is not limited to them in its effects.

15 'Substantive theory identifies the values embodied in current designs with the essence of technology as such ... By contrast, the design critique relates the values embodied in technology to a social hegemony' (Feenberg 2002: 64).

16 Identifying the authoritative character of technology with its purported rationality is now so ingrained in the Marxist tradition as to be almost a habit. For example, Gregory Claeys, in his introduction to Marx and Marxism, suggests that, for Marx, 'technological rationality seemingly defines the limits of political will' (2018: 211), yet the phrase never appears in any of Marx's texts.

17 There is a parallel here with feminist theorists Dona Haraway (1991) and N. Katherine Hayles (1999), who also contrast the incorporation of technology, which involves submission and habituation to its behavioural templates, with 
inscription, which is a process of refashioning, rewriting the tool - quite literally, in the age of programmable devices and platforms. Like Feenberg, they identify positive political potential in these practices of inscription.

18 In this respect Feenberg's critique resembles that of Michel Foucault, who also contrives to place the hard sciences outside the purview of his critique of epistemology (for discussion, see Eribon 2011: 358-370).

19 Feenberg is quite selective in his use of Foucault's ideas. It is worth noting that the latter rejected a strong association of his approach with that of critical theory, saying: 'I don't think that the Frankfurt School can accept that what we need to do is not recover our lost identity, or liberate our imprisoned nature, or discover our fundamental truth; rather, it is to move towards something altogether different' (2002: 275). This remark applies equally well to Feenberg's project of redeeming technology by way of progressive rationalization articulated through democratic technical politics.

20 The priority of the pathological over the healthy was explored by Foucault's mentor George Canguilheim (2007). 